\title{
Glucose Regulation in Preterm Newborn Infants
}

\author{
Delphine Mitanchez
}

Université Pierre et Marie Curie, Faculté de Médecine; Service de néonatologie, AP-HP,

Hôpital Armand-Trousseau, Paris, France

\section{Key Words}

Glucose homeostasis - Preterm newborn infants • Insulin • Proinsulin • Hypoglycemia • Hyperglycemia • Insulin resistance $\cdot$ Gluconeogenesis $\cdot$ Glycogenolysis

\begin{abstract}
After birth, continuous transplacental transfer of glucose is interrupted. Neonates have to provide brain and vital organs with sufficient glucose. In term newborn infants, this is accomplished through well-coordinated hormonal and metabolic adaptive changes. During the first week of life, preterm infants are at high risk of abnormal glucose homeostasis. They are at risk of hypoglycemia due to limited glycogen and fat stores that should have occurred in the third trimester. Continuous glucose infusion is always required soon after birth to maintain the glucose level. However, under such conditions, many preterm infants develop hyperglycemia. Defective islet $\beta$-cell processing of proinsulin is likely related to hyperglycemia. There is also evidence that preterm infants are partially resistant to insulin. By contrast with adults, hepatic glucose production is not suppressed during parenteral glucose infusion. Exogenous insulin infusion partially reduces endogenous glucose production in preterm newborn infants. This treatment is efficient and safe when used with caution. More research is needed to understand the specificity of glucose homeostasis in preterm infants and to evaluate the long-term consequences of metabolic and nutritional support during early life.
\end{abstract}

Copyright $\odot 2007$ S. Karger AG, Basel
Transition from fetal to neonatal life requires a number of adaptations which are more difficult to accomplish by preterm than term newborn infants. Knowledge of key regulatory mechanisms of glucose homeostasis during fetal life and the early neonatal period is essential to understand the specificities of glucose homeostasis in preterm infants. During early postnatal life, infants born prematurely are at high risk of altered glucose homeostasis. Early continuous glucose infusion is always required in preterm infants to prevent hypoglycemia and to provide adequate nutritional support. However, many of them develop hyperglycemia during the first week of life when receiving glucose infusion. This review looks at physiological aspects of glucose metabolism in the fetus and term neonate and their disturbances in preterm infants.

\section{Fetal Glucose Metabolism}

Glucose is the main energy source for fetal development. Glucose homeostasis during fetal life depends entirely on continuous placental glucose transfer. Indeed, no significant fetal glucose production has been demonstrated. The fetal glucose pool is in equilibrium with that of the mother [1].

The fetal endocrine milieu is characterized by high plasma insulin and low plasma glucagon levels. Circulating insulin can be detected after 13 weeks of gestation. The fetal pancreas is able to release insulin in response to 
glucose and amino acids after the 20th week of gestation. Insulin action is modulated by glucocorticoids which induce the expression of transcriptional factors. These factors regulate the expression of enzymes related to glycogen and lipids synthesis. Insulin is inactive until the onset of corticoid action in the second trimester. This explains why glycogen storage does not occur before the 27 th week [2].

Glycogen synthesis is initiated during the second trimester of gestation and increases slowly until 36 weeks. Then hepatic glycogen content increases quickly until full term to reach $50 \mathrm{mg} / \mathrm{g}$ of tissue. Although most gluconeogenic enzymes have a significant activity in the liver of the near-term fetus, gluconeogenesis is inhibited by the presence of high insulin levels and is not functional in utero. Insulin enhances fatty acid synthesis in the liver and glucose uptake in adipose tissue leading to triglyceride synthesis. Human placenta is permeable to triglycerides, free fatty acids and glycerol. Taken together these processes permit fat storage in adipose tissue during third trimester. Fat content of term neonates reaches $16 \%$ of body weight at birth [3]. Glycogen and fat constitute stores available for metabolic changes at birth.

\section{Early Neonatal Glucose Metabolism in the Term Neonate}

Metabolic changes at birth are regulated in order to ensure continuous fuel supply to the brain and vital organs until enteral feeding provides adequate energy needs.

\section{Endocrine Response at Birth}

Constant maternal glucose supply is interrupted by umbilical cord section. It is followed by an endocrine stress response characterized by a huge peak of plasma catecholamine $(\times 3-10)$, an increase in plasma glucagon $(\times 3-5)$ and in glucagon receptors and an increase in plasma cortisol level. Plasma insulin level decreases and leads to a low insulin/glucagon molar ratio which is essential for inducing hepatic glycogenolysis and gluconeogenesis [1]. Glucagon and catecholamine activate adenylcyclase which causes an increase in intracellular cyclic AMP and promotes glycogenolysis, lipolysis and gluconeogenesis. Glucocorticoids act in synergy with glucagon and catecholamine. They also promote muscle protein breakdown and lipolysis, thus increasing the availability of gluconeogenic substrates.

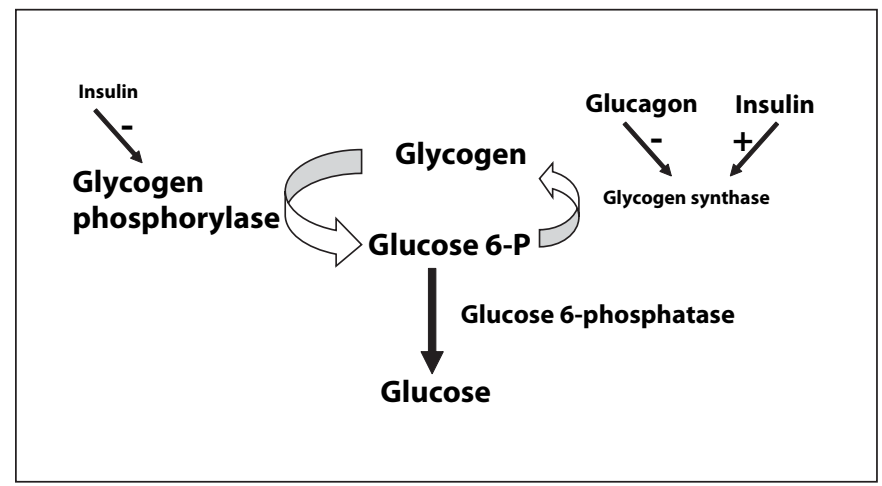

Fig. 1. Glycogenesis and glycogenolysis pathways. Insulin activates glycogen synthase and inhibits glycogen phosphorylase. Glucagon inhibits glycogen synthase. At birth, the low insulin/ glucagon ratio acts in favor of glycogenolysis.

\section{Hepatic Glucose Production}

The aim of neonatal glucose homeostasis is to provide the brain and other vital organs with sufficient glucose as a key energy source. Glycogenolysis, gluconeogenesis, lipolysis, fatty acid oxidation and proteolysis contribute to this homeostasis.

Hepatic glucose output through glycogenolysis and gluconeogenesis is the only source of glucose until feeding is established. Hepatic glucose production has been estimated to $4-6 \mathrm{mg} / \mathrm{kg} / \mathrm{min}$ in term neonates. Initial increase in plasma glucagon leads to rapid glycogen breakdown through activating glycogen phosphorylase (fig. 1). Liver glycogen stores are depleted from 50 to $5 \mathrm{mg} / \mathrm{g}$ within $12 \mathrm{~h}$ of birth. Gluconeogenesis is not active immediately after birth because of the low activity of the cytosolic phosphoenolpyruvate carboxykinase (PEPCK), the rate-limiting enzyme of this metabolic pathway (fig. 2). Liver PEPCK gene and cytosolic enzyme activity increases markedly after birth in response to the decrease in the plasma insulin/glucagon molar ratio. Glucagon and catecholamine surges increase intracellular cAMP that acts on the cAMP response element (CRE) of the promoter of the PEPCK gene. Thus, synthesis of PEPCK mRNA starts at birth $[4,5]$. Glucose production by the way of gluconeogenesis starts $2 \mathrm{~h}$ after birth and is at its peak after $12 \mathrm{~h}$. Alanine resulting from protein breakdown and glycerol resulting from triglyceride breakdown are the two major gluconeogenic substrates. Delivery of fatty acids to the liver and their further oxidation support gluconeogenesis by providing ATP, acetyl-CoA and reducing equivalents NAD/NADH (fig. 2) [5]. 


\section{Alternative Substrates}

Glucose oxidation can only support $70 \%$ of the brain energy needs. Ketone body and lactate are important alternative fuels to spare glucose requirement. Long chain fatty acid oxidation and ketone body production are very low in the fetal liver. Hepatic ketogenesis is limited within the first hours after birth and markedly increases during the first $24 \mathrm{~h}$ following birth. From $12 \mathrm{~h}$ of age term infants show high ketone body turnover rate (12-22 $\mu \mathrm{mol} / \mathrm{min})$. During days 2 and 3 after birth they exhibit high ketone body concentrations [6,7]. There is evidence that when infants are of appropriate weight for gestational age, ketone body production provides alternative fuels for brain metabolism [7].

\section{Glucose Transporters}

Facilitative glucose transporters (GLUT) use the diffusion gradient of glucose across plasma membrane and exhibit different kinetic properties and tissue expression profiles (fig. 3). GLUT-1 is ubiquitously expressed and is particularly abundant in the blood-brain barrier and erythrocytes. GLUT-2 is primarily expressed in pancreatic $\beta$-cells, liver and kidney. In $\beta$-cells GLUT- 2 plays a role in the glucose-sensing mechanism. It is expressed on the sinusoidal membrane of hepatocytes and allows bidirectional transport of glucose. GLUT-3 has a high affinity for glucose. It is expressed in the brain where glucose requirement is very high. The insulin-responsive glucose transporter GLUT- 4 is expressed in heart, skeletal muscle and adipose tissue. Insulin acts by stimulating the translocation of GLUT-4 from intracellular specific vesicle stores to the plasma membrane [8].

Data from a number of species demonstrate that during fetal and early neonatal life the high-affinity glucose transporter GLUT-1 is the predominant isoform in all tissues $[2,9]$. It allows an appropriate response to the high metabolic requirement from fetal growth and development. It progressively decreases after birth, being replaced by specific isoforms in each tissue [10].

\section{Altered Glucose Metabolism in Preterm Infants}

\section{Hypoglycemia}

There is a larger fall in blood glucose concentration in preterm than in term infants within the first few hours after birth. Liver glycogen stores are limited in neonates born before 28 weeks of gestation because glycogen storage primarily takes place during the third trimester. One recent study showed that in infants less than 32 weeks'

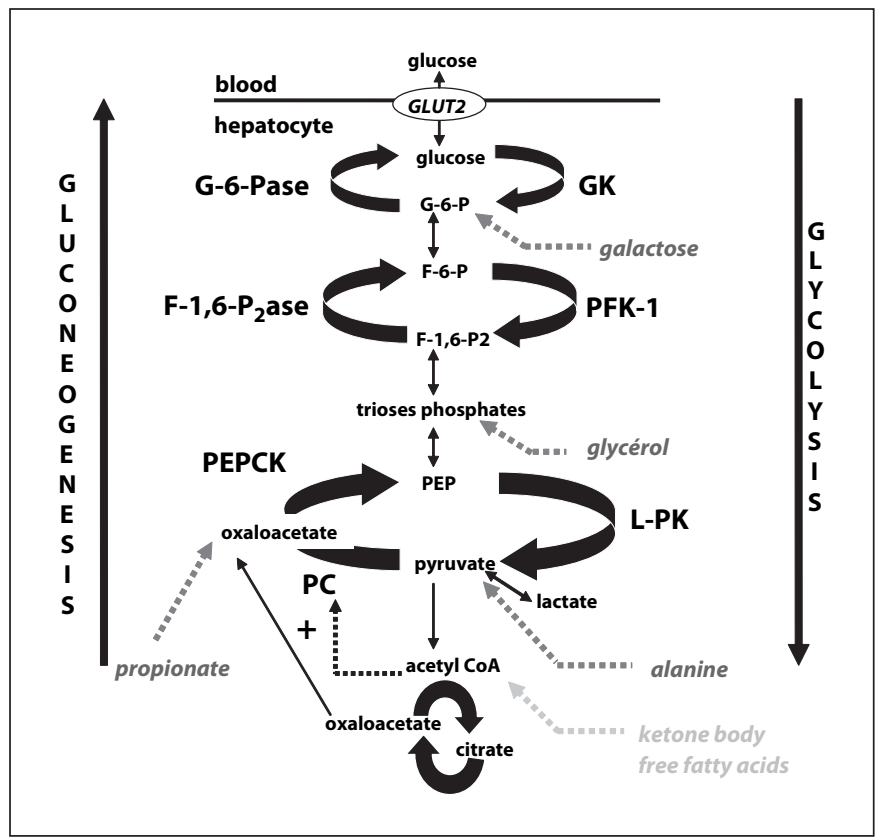

Fig. 2. Glycolysis and gluconeogenesis pathways. Precursors for gluconeogenesis are indicated in dark grey. Ketone body and free fatty acids generate acetyl-CoA (light grey). G-6-Pase = Glucose 6-phosphatase; GK = glucokinase; F-1,6-Pase = fructose 2, 6-biphosphatase; PFK-1 = phosphofructokinase-1; PEPCK = phosphoenolpyruvate carboxykinase; L-PK = L-type pyruvate kinase; $\mathrm{PC}=$ pyruvate carboxylase $\mathrm{PEP}=$ phosphoenolpyruvate.

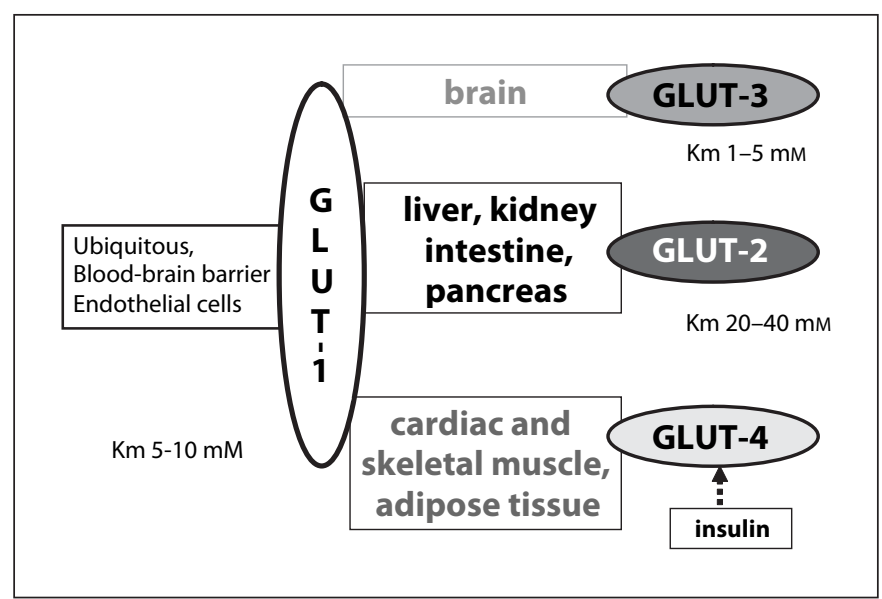

Fig. 3. Facilitative glucose transporters. Glut-1 has a low $\mathrm{K}_{\mathrm{m}}$ and is a high-affinity glucose transporter. It is found in most tissues. The high-affinity transporter Glut-3 is the brain type glucose transporter. Glut-2 is a low-affinity glucose transporter. It is expressed in cells as pancreatic $\beta$-cell and hepatocyte, where the metabolism is regulated in response to small variations in blood glucose concentration. The insulin responsive transporter Glut- 4 is predominantly found in cardiac and skeletal muscle and adipose tissue. 
gestational age and 3-6 days' postnatal age glucose production increased in response to glucagon [11]. This was mainly due to an increase in glycogenolysis. However, the amount of glucose released was low in comparison with adults, especially in regard of their higher glucose needs. Gluconeogenesis is then the major pathway of glucose production in these premature neonates. The time necessary to induce the enzymes involved in gluconeogenesis and the absence of stored glycogen make hypoglycemia almost unavoidable in the first few hours after birth if exogenous glucose is not administrated.

Some findings have suggested that gluconeogenic ability is limited, possibly due to immaturity of enzymatic pathways. The activity of microsomal glucose-6-phosphatase (the final enzyme of both glycogenolysis and gluconeogenesis) has been reported to be in the low range in preterm infants [12]. Circulating levels of gluconeogenic substrates have been reported to be rather high: lactate and pyruvate concentrations are similar in preterm infants to those of term infants but alanine concentration is lower $(0.18$ vs. $0.26 \mathrm{mmol} / \mathrm{l}, \mathrm{p}<0.01)$ [7]. Very preterm infants generate glycerol via hydrolysis of their small fat stores and they convert glycerol into glucose. In infants born as early as 25-26 weeks of gestation parenteral glycerol enhances gluconeogenesis [13]. On the other hand, administration of alanine did not enhance gluconeogenesis, despite a high plasma alanine level [14]. Glycerol enters the gluconeogenic pathway at the level of the triose phosphate pool whereas alanine enters at the pyruvate level (fig. 2). The lack of stimulation of gluconeogenesis by alanine supply could be consistent with a low activity of enzymes involved in gluconeogenesis downstream of triose phosphate.

Ketogenesis is severely limited in preterm infants. They lack of fat stores in adipose tissue as fat represents less than $2 \%$ of total body weight. Compared with term infants they have low ketone body and free fatty acid concentrations during the first postnatal week, with no rise despite low blood glucose levels [7]. This may be related to a combined failure of lipolysis and ketogenesis. However, in contrast to term infants, preterm babies demonstrate a positive relationship between blood ketone body concentrations and the volume of enteral feeding. It may be so because enteral feeding induces ketogenesis enzymes [7].

Thus, there is evidence that preterm infants are at higher risk for hypoglycemia. Other clinical conditions which are associated with hypoglycemia are common in this population. They include perinatal asphyxia, hypoxia, sepsis, and hypothermia. Preterm infants appear less

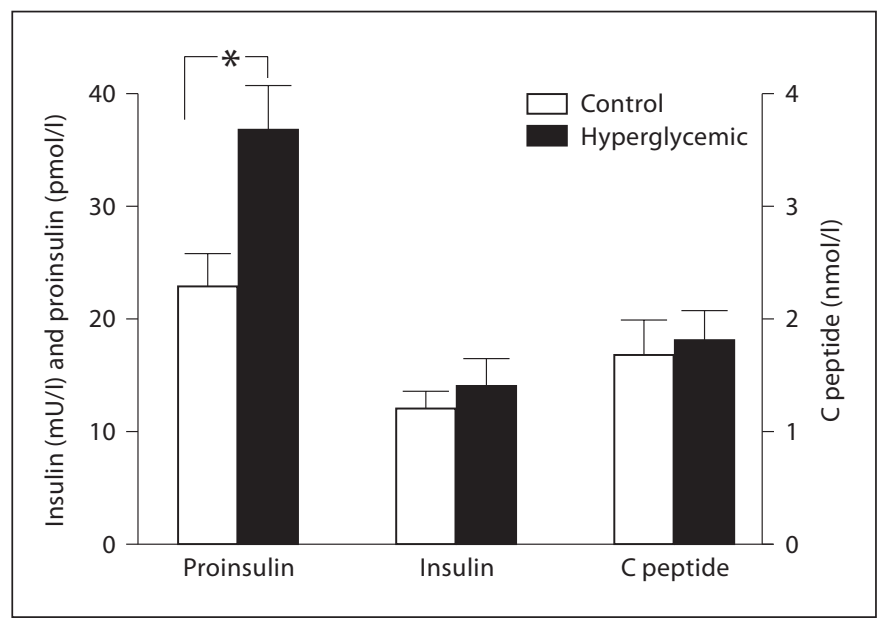

Fig. 4. Proinsulin, insulin and C-peptide concentrations in control (nonhyperglycemic) and in hyperglycemic preterm infants. In both groups gestational age was less than 30 weeks. Blood samples were obtained in the hyperglycemic group when capillary glycemia was found at least twice above $11 \mathrm{mmol} / \mathrm{l}$ before insulin infusion was started. In the other group, blood samples were collected during the first week of life. Median value of plasma glucose concentration was $16.0 \mathrm{mmol} / \mathrm{l}$ [9.1-29] and $5.0 \mathrm{mmol} / \mathrm{l}$ [4.3-7.6], respectively, in each group. ${ }^{*} \mathrm{p}=0.006$. Values are mean \pm SEM. From Mitanchez-Mokhtari et al. [24].

able to counterbalance those troubles than term infants and to provide alternative fuels for the brain. Even moderate hypoglycemia can lead to an adverse neurodevelopmental outcome $[15,16]$. Hypoglycemia should be avoided by treating the underlying condition, providing optimal thermal environment and adequate parenteral energy immediately after birth. Enteral feeding is a stimulus for postnatal metabolic adaptation. Thus, early milk feeding should be encouraged as soon as possible when tolerated, even at a minimal level.

\section{Hyperglycemia}

As mentioned above continuous glucose infusion is always required in preterm infants to maintain glucose level. However, under such conditions neonatal hyperglycemia is commonly observed during the first week of life in infants born before 30 weeks of gestation [17]. The neonate weighing less than $1,000 \mathrm{~g}$ is 18 times more likely to develop hyperglycemia than one weighing more than $2,000 \mathrm{~g}$ [18]. In a large cohort study of infants weighing less than $1,000 \mathrm{~g}$, the occurrence and the level of hyperglycemia significantly decreased when birth weight increased [19]. This emphasizes that the degree of immaturity plays a central role in the physiopathology of hyper- 
Table 1. Proinsulin, insulin, C-peptide, glucagon levels and insulin/glucagon ratio (median and range) in hyperglycemic preterm, nonhyperglycemic preterm and full-term neonates

\begin{tabular}{llllll}
\hline & $\begin{array}{l}\text { Proinsulin } \\
\mathrm{mU} / \mathrm{l}\end{array}$ & $\begin{array}{l}\text { Insulin } \\
\mathrm{mU} / \mathrm{l}\end{array}$ & $\begin{array}{l}\text { C-peptide } \\
\mathrm{nmol} / \mathrm{l}\end{array}$ & $\begin{array}{l}\text { Glucagon } \\
\text { pmol/l }\end{array}$ & $\begin{array}{l}\text { Insulin/ } \\
\text { glucagon }\end{array}$ \\
\hline Hyperglycemic preterm $(\mathrm{n}=15)$ & $39.9^{\mathrm{a}} \mathrm{b}$ & $9.4^{\mathrm{b}}$ & $1.6^{\mathrm{b}}$ & $146^{\mathrm{c}}$ & $2.0^{\mathrm{b}}$ \\
& $16.9-63.7$ & $2.3-27.3$ & $0.37-3.3$ & $84-481$ & $0.24-7.7$ \\
& $20.75^{\mathrm{b}}$ & $8.6^{\mathrm{b}}$ & $1.1^{\mathrm{b}}$ & $104^{\mathrm{c}}$ & $2.0^{\mathrm{b}}$ \\
Nonhyperglycemic preterm $(\mathrm{n}=12)$ & $11.1-33.5$ & $5.2-23.3$ & $0.56-4.3$ & $78-409$ & $0.42-7.2$ \\
& 15.9 & 2.5 & 0.52 & 224 & 0.42 \\
Full-term neonates $(\mathrm{n}=19)$ & $8.5-66.4$ & $0.6-13.2$ & $0.20-2.7$ & $53-624$ & $0.033-2.6$ \\
\hline
\end{tabular}

In both preterm groups gestational age was less than 30 weeks. Blood samples were obtained in the hyperglycemic group when capillary glycemia was found at least twice above $11 \mathrm{mmol} / \mathrm{l}$, before insulin infusion was started. In both other groups, blood samples were collected during the first week of life.

a Significantly higher than nonhyperglycemic preterms $(\mathrm{p}=0.006) .{ }^{\mathrm{b}}$ Significantly higher than in full-term neonates $\left(\mathrm{p}<10^{3}\right)$. ${ }^{c}$ Significantly lower than the full-term neonates $(\mathrm{p}=0.028)$.

glycemia. There are many conditions that are associated with neonatal hyperglycemia such as stress, drug treatment by steroids or methylxanthines and administration of glucose at excessive rates. Hyperglycemia may appear independently of these conditions when glucose is infused at a rate that matches basal requirement $(4-7 \mathrm{mg} /$ $\mathrm{kg} / \mathrm{min}$ ). Hyperglycemia in the neonate is statistically defined as blood glucose concentration greater than $7 \mathrm{mmol} / \mathrm{l}$ or plasma glucose concentration greater than $8.25 \mathrm{mmol} / \mathrm{l}[19]$.

Many have stressed the risk of glycosuria, osmotic diuresis and dehydration although it has been stated that neonates are very unlikely to develop osmotic diuresis due to glycosuria while they have blood glucose below 12 $\mathrm{mmol} / \mathrm{l}[17,20]$. Hyperglycemia has been associated to a higher risk of intraventricular hemorrhage. However, causal relationship has not been proven because it is not possible to say whether severe hyperglycemia damages the brain or whether children who have suffered damage to the brain are at higher risk of developing hyperglycemia $[2,17]$.

\section{Pathophysiologic Basis of Hyperglycemia}

Several studies have shown that plasma glucose and insulin levels were higher in preterm than in term infants [21-23]. In hyperglycemic preterm infants pancreatic $\beta$ cells are sensitive to changes in blood glucose concentration $[24,25]$. However, pancreatic $\beta$-cells only increased the secretion of the nonprocessed proinsulin in response to hyperglycemia (fig. 4). Proinsulin is 10 -fold less active than mature insulin and does not allow controlling plas- ma glucose levels. Hyperglycemia is likely related to a defective islet $\beta$-cell processing of proinsulin [24]. There is also evidence that preterm infants are partially resistant to insulin action as documented by higher proinsulin and insulin levels than in term infants (table 1) [24]. Furthermore, using the euglycemic-hyperinsulinemic clamp technique Farrag et al. [26] showed that insulin at a relatively low concentration reduced significantly hepatic glucose production in the preterm infants. Higher insulin infusion rates which led to a 10 -fold higher plasma insulin concentration did not significantly enhance this effect. The authors concluded that this pattern of response of glucose production to insulin is consistent with the definition of insulin unresponsiveness and may be related to a postreceptor defect. Others have shown that by contrast with adults hepatic glucose production persisted during parenteral glucose infusion in preterm infants $[27,28]$. We observed that plasma glucagon levels were lower and the insulin/glucagon ratio was higher in preterm than in term infants (table 1). These hormonal conditions are not those required for activating gluconeogenesis. Thus, persistent gluconeogenesis may not be the cause of persistent glucose production during hyperglycemia. The specific glucose transporter GLUT-2 allows glucose uptake or release by the liver in response to changes in plasma glucose concentration. Once inside the hepatocyte, glucose is converted into glucose-6-phosphate by glucokinase, before entering in the various metabolic pathways. Glucokinase is an insulin-dependent enzyme. It may be decreased in the liver of preterm infants due to the relative defect in insulin activity and/or 
sensitivity [29]. This should lead to an excessive output of glucose in the circulation because hepatocytes are unable to metabolize glucose efficiently. In addition, insulinsensitive tissues such as adipose tissue and skeletal and cardiac muscles are less abundant in preterm than in term neonates. This, associated with insulin resistance, may lead to diminished peripheral glucose uptake and may also contribute to hyperglycemia.

\section{Management of Hyperglycemia}

As discussed above there are many conditions associated with neonatal hyperglycemia. Treating the underlying condition and avoiding the precipitating factors are basic concepts in the management of hyperglycemia. Excessive glucose administration rate should be avoided as there is a significant correlation between the rate of glucose infusion and plasma glucose concentration. Glucose infusion should be maintained at a rate of at least 4$7 \mathrm{mg} / \mathrm{kg} / \mathrm{min}$ to match basal glucose requirement [19]. Reducing glucose infusion to an extremely low rate to manage hyperglycemia significantly reduces caloric and protein intakes: depriving these neonates of protein and carbohydrate substrates may have long-term effects on their growth and development. Exogenous insulin therapy should be administered when blood glucose concentration exceeds $12 \mathrm{mmol} / \mathrm{l}$ (>215 mg/dl) [17]. The euglycemic-hyperinsulinic clamp technique was used to evaluate insulin sensitivity [26]. This led to recommend the use of insulin infusion at a starting rate of $1 \mathrm{mU} / \mathrm{kg} / \mathrm{min}$, which may be gradually increased to $2 \mathrm{mU} / \mathrm{kg} / \mathrm{min}[19$, 18]. At the rate of $1 \mathrm{mU} / \mathrm{kg} / \mathrm{min}$ a $44 \%$ reduction in glucose production was documented [26]. The blood glucose concentration should be maintained within an acceptable range (i.e. 5.5 to $8.25 \mathrm{mmol} / \mathrm{l}$ ) to avoid the risk of hypoglycemia. It is important to prevent adherence of insulin to the plastic tubing, especially when using low concentration and low flow rate. In order to ensure regular rate of insulin infusion it is recommended to flush the tubing with at least $5-10 \mathrm{ml}$ of a solution containing insulin at a concentration of $1-5 \mathrm{U} / \mathrm{ml}$ before initiating continuous insulin infusion in the patient $[30,31]$.

Glucose homeostasis in the neonate is a complex process which involves multiple metabolic pathways. In preterm infants, immaturity of many functions makes this regulation more complex and many of its aspects, as physiopathology of hyperglycemia, require further investigations both at physiological and molecular levels. Consequences of being exposed to extrauterine environment during the period corresponding to the third trimester of pregnancy have not either been fully evaluated. Recent data indicate that insulin resistance is present in children 4-10 years old who were born prematurely [32]. The authors proposed that the decrease in insulin sensitivity predisposes preterm infants to type 2 diabetes mellitus in adulthood as already demonstrated among term infants born small for gestational age [33-35]. These results mean that extra-uterine environmental manipulations during the vulnerable period of adaptive change in the third trimester may influence future functional adaptations. More research is needed to identify long-term consequences of metabolic and nutritional support during early life in preterm newborn infants.

\section{Acknowledgements}

The author thanks Professors Jean Girard and Francis Gold and Drs Valérie Datin-Dorriere and Fanny Bajolle for assistance in revising the manuscript.

\section{References}

1 Menon RK, Sperling MA: Carbohydrate metabolism. Semin Perinatol 1988;12:157-162.

2 Mena P, Llanos A, Uauy R: Insulin homeostasis in the extremely low birth weight infant. Semin Perinatol 2001;25:436-446.

3 Ward Platt M, Deshpande S: Metabolic adaptation at birth. Semin Fetal Neonatal Med 2005; 10:341-350.

4 Girard J: Gluconeogenesis in late fetal and early neonatal life. Biol Neonate 1986;50: 237-258.

5 Girard J: Metabolic adaptations to change of nutrition at birth. Biol Neonate 1990;58 (suppl 1):3-15.

\footnotetext{
6 Bougneres P, Lemmel C, Ferré P, Bier D: Ketone body transport in the human neonate and infant. J Clin Invest 1986;77:42-48.

7 Hawdon JM, Ward Platt MP, Aynsley-Green A: Patterns of metabolic adaptation for preterm and term infants in the first neonatal week. Arch Dis Child 1992;67:357-365.

-8 Wood I, Trayhurn P: Glucose transporters (GLUT and SGLT): expanded families of sugar glucose transport proteins. Br J Nutr 2003;89:3-9.

-9 Nualart F, Godoy A, Reinicke K: Expression of the hexose transporters GLUT-1 and

10 Postic C, Leturque A, Printz RL, Maulard P, Loizeau M, Granner DK, Girard J: Development and regulation of glucose transporter and hexokinase expression in rat. Am J Physiol 1994;266:E548-E559.

11 van Kempen AA, Ackermans MT, Endert E, Koh DK, Sauerwein HP: Glucose production in response to glucagon is comparable in preterm AGA and SGA infants. Clin Nutr 2005; 24:727-736

12 Hume R, Burchell A: Abnormal expression of glucose-6-phosphatase in preterm infants. Arch Dis Child 1993;68:202-204.
} GLUT-2 during the early development of the human brain. Brain Res 1999;824:97-104. 
13 Sunehag AL: Parenteral glycerol enhances gluconeogenesis in very premature infants. Pediatr Res 2003;53:635-641.

14 van Kempen AA, Romijn JA, Ruiter AF, Endert E, Weverling GJ, Kok JH, Sauerwein HP: Alanine administration does not stimulate gluconeogenesis in preterm infants. Metabolism 2003;52:945-949.

-15 Lucas A, Morley R, Cole TJ: Adverse neurodevelopmental outcome of moderate neonatal hypoglycaemia. BMJ 1988;297:13041308.

-16 Duvanel CB, Fawer CL, Cotting J, Hohlfeld P, Matthieu JM: Long-term effects of neonatal hypoglycemia on brain growth and psychomotor development in small-for-gestational-age preterm infants. J Pediatr 1999; 134:492-498.

$\checkmark 17$ Hey E: Hyperglycaemia and the very preterm baby. Semin Fetal Neonatal Med 2005; 10:377-387.

18 Dweck H, Cassady G: Glucose intolerance in infant of very low birth weight. I. Incidence of hyperglycemia in infants of birth weight 1.100 or less. Pediatrics 1974;53:189-195.

-19 Farrag HM, Cowett RM: Glucose homeostasis in the micropremie. Clin Perinatol 2000; 27:1-22.

-20 Coulthard MG, Hey EN: Renal processing of glucose in well and sick neonates. Arch Dis Child Fetal Neonatal Ed 1999;81:F92-98.
21 Hawdon JM, Aynsley-Green A, Alberti KG, Ward Platt MP: The role of pancreatic insulin secretion in neonatal glucoregulation. I. Healthy term and preterm infants. Arch Dis Child 1993;68:274-279.

22 Tyrala EE, Chen X, Boden G: Glucose metabolism in the infant weighing less than 1,100 grams. J Pediatr 1994;125:283-287.

23 Pollak A, Cowett RM, Schwartz R, Oh W: Glucose disposal in low-birth-weight infants during steady-state hyperglycemia: effects of exogenous insulin administration. Pediatrics 1978;61:546-549.

24 Mitanchez-Mokhtari D, Lahlou N, Kieffer F, Magny JF, Roger M, Voyer M: Both relative insulin resistance and defective islet betacell processing of proinsulin are responsible for transient hyperglycemia in extremely preterm infants. Pediatrics 2004;113:537541.

-25 Hawdon JM, Hubbard M, Hales CN, Clark PM: Use of specific immunoradiometric assay to determine preterm neonatal insulinglucose relations. Arch Dis Child Fetal Neonatal Ed 1995;73:F166-F169.

26 Farrag HM, Nawrath LM, Healey JE, Dorcus EJ, Rapoza RE, Oh W, Cowett RM: Persistent glucose production and greater peripheral sensitivity to insulin in the neonate vs. the adult. Am J Physiol 1997;272:E86-E93.

27 Sunehag A, Gustafsson J, Ewald U: Very immature infants $(<$ or $=30 \mathrm{wk}$ ) respond to glucose infusion with incomplete suppression of glucose production. Pediatr Res 1994;36 550-555.
28 Cowett RM, Oh W, Schwartz R: Persistent glucose production during glucose infusion in the neonate. J Clin Invest 1983;71:467475.

-29 Iynedjian PB, Jotterand D, Nouspikel T, Asfari M, Pilot PR: Transcriptional induction of glucokinase gene by insulin in cultured liver cells and its repression by the glucagoncAMP system. J Biol Chem 1989;264:2182421829.

30 Furiola M, Friedberg M, DuRant R, Aschner $\mathrm{J}$ : Effect of flow rate and insulin priming on the recovery of insulin from microbore infusion tubing. Pediatrics 1998;102:1401-1406.

31 Hewson M, Nawadra V, Olivier J, Odgers C, Plummers J, Simmer K: Insulin infusion in the neonatal unit: delivery variation due to absorption. J Paediatr Child Health 2000;36: 216-220.

32 Hofman PL, Regan F, Jackson WE, Jefferies C, Knight DB, Robinson EM, Cutfield WS: Premature birth and later insulin resistance. N Engl J Med 2004;351:2179-2186.

-33 Hales CN, Barker DJ, Clark PM, Cox LJ, Fall C, Osmond C, Winter PD: Fetal and infant growth and impaired glucose tolerance at age 64. BMJ 1991;303:1019-1022.

34 Hales CN, Ozanne SE: The dangerous road of catch-up growth. J Physiol 2003;547:510.

35 Singhal A, Lucas A: Early origins of cardiovascular disease: is there a unifying hypothesis? Lancet 2004;363:1642-1645. 